\title{
Performance Impact Research of Mobile Communication System from DTX Setting
}

\author{
Shuizhen Xie \\ School of electronic engineering , Jiujiang University, Jiujiang 330025, China \\ xieshuizhen@126.com
}

Keywords: DTX, Mobile Communication System, MOS value.

\begin{abstract}
In order to research the performance impact of the mobile communication system from DTX setting, we test the partial section in Jiujiang city of Jiangxi province. The research shows if we import DTX technology in the mobile communication network system, it is obviously can improve the voice MOS value and the call quality. It will reduce the wireless system interference and promote the user perception.
\end{abstract}

\section{Introduction}

The talker and the listener place the equal split time during the normal communication. During the working of the mobile communication network, only the background noise exists if there has no voice single in the silent period. If we transmit all these messages to the network, it will waste the system resources and will lead the system interference. In order to reduce the whole transmit level of the mobile communication system, we use voice activity detection (VAD) and discontinuous transmission (DTX) to improve the system effectiveness and save the power consumption of the wireless sender (especially the mobile station). During the call, we use cold block 260bit/20ms to transmit the signal. And if it is the silence time, it will use SID 260bit/480ms to create the comfort background noise. The technology of not sending the information when the voice coder tests the call gap is the DTX (Discontinuous transmission). DTX and CNG technology can make 13Kb/s code during the call and send comfort noise with 500b/s code in the pause period. This method can reduce the average speed. If we use the same code rate all along, it is the waste of the single channel resources. DTX and CNG technology can control the coder with different code rate based on the voice section and background noise. It can improve the channel utilization and reduce the noise interference.

\section{DTX Parameter Introduction}

Definition. Discrete transmission (DTX) is the process that the phone signal will not be transmitted when the communication stopped. The parameter of "discrete transmission (DTX)" controls the mobile radio station to use the DTX or not during the communication.

Pattern .The network operator can set the DTX permission, which means setting the DTX parameters. This parameter has three ways to measure value. "0" means the mobile radio station can use DTX; "1" means the mobile radio station has to use DTX; "2" means the mobile radio station cannot use the DTX.

Transmission. Parameter DTX contained in the information unit “cell option” , which can transmit during the period of system messages (BCCH and SACCH).

Settings and influences. DTX application has limited influence to the voice quality. It has two superiorities: effectively reducing of the wireless channel interference, which will improve the average network quality of connection. At the same time, DTX application can greatly save the power consumption of the mobile station. 
Test section selection and cell option statistics. Based on the experimental requirement, here we test the partial section in Jiujiang city of Jiangxi province. The departed test shows there have 122 occupied cells, which involved 3 BSC (JIJBSC31G, JIJBSC37G, JIJBSC43G).

\section{Contrast Discussion Of The Experimental Effectiveness}

Check the key index comparison . The quality contrast, after DTX open is in figure 1 and table 1.

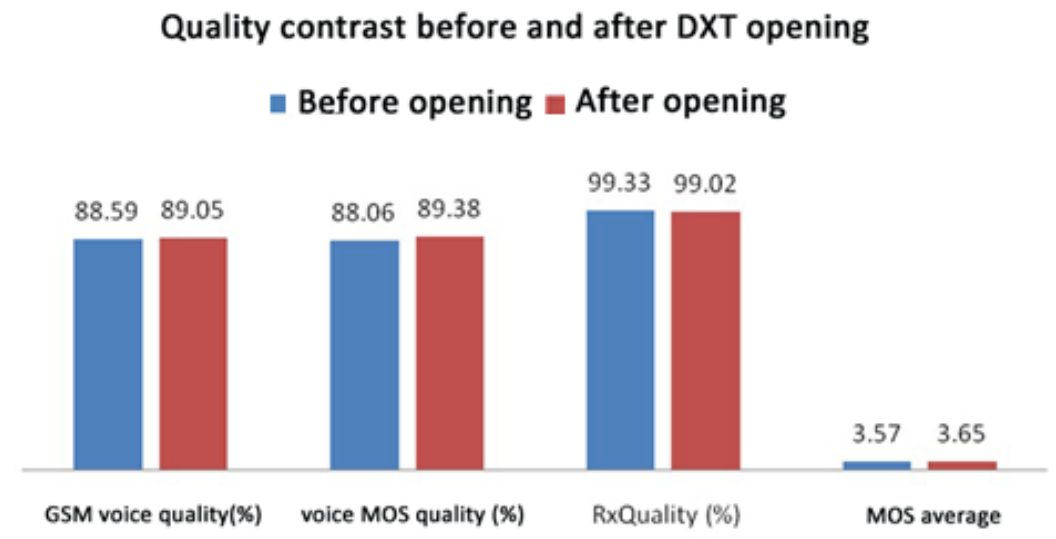

Fig. 1 Quality contrast before after DXT opening

Table 1 Quality comparison before and after the DTX opening

\begin{tabular}{|c|c|c|c|c|c|c|c|c|c|c|}
\hline & $\begin{array}{c}\text { Success } \\
\text { rate of } \\
\text { the full } \\
\text { call (\%) }\end{array}$ & $\begin{array}{c}\text { GSM } \\
\text { Voice } \\
\text { quality }\end{array}$ & $\begin{array}{c}\text { Voice } \\
\text { quality } \\
\text { of } \\
\text { MOS } \\
(\%)\end{array}$ & $\begin{array}{c}\text { RxQuality } \\
(\%)\end{array}$ & $\begin{array}{c}\text { MOS } \\
\text { Averag } \\
\text { e }\end{array}$ & $\begin{array}{c}\text { RxQuality0-5\& } \\
\text { MOS>=2.8 } \\
\text { Sample quantity }\end{array}$ & $\begin{array}{c}\text { MOS } \\
\text { Sample } \\
\text { quantity }\end{array}$ & $\begin{array}{c}\text { MOS } \\
900 \text { samples } \\
\text { quality } \\
(\%)\end{array}$ & $\begin{array}{c}\text { MOS18 } \\
\text { samples } \\
\text { quality } \\
(\%)\end{array}$ & $\begin{array}{c}\text { Call } \\
\text { Quas } \\
(\%)\end{array}$ \\
\hline $\begin{array}{c}\text { Before } \\
\text { opening }\end{array}$ & 100 & 88.59 & 88.06 & 99.33 & 3.57 & 3777 & 4235 & 89.26 & 84.87 & 96.88 \\
\hline $\begin{array}{c}\text { After } \\
\text { opening }\end{array}$ & 100 & 89.05 & 89.38 & 99.02 & 3.65 & 3912 & 4350 & 92.07 & 85.32 & 100 \\
\hline
\end{tabular}

Analyze the comparison before and after the DTX opening, each index has the promotion. GSM voice quality increases $0.46 \%$, voice MOS quality increases $1.22 \%$, and the MOS average improves from 3.57 to 3.65. Otherwise, the RxQuality decreases $0.31 \%$.

MOS distribution contrast.The MOS distribution contrast before and after the DTX opening is in figure 2 and table 2.

\section{MOS distribution contrast before and after the DTX opening}

Rate before opening (\%) $\quad$ Rate after opening (\%)

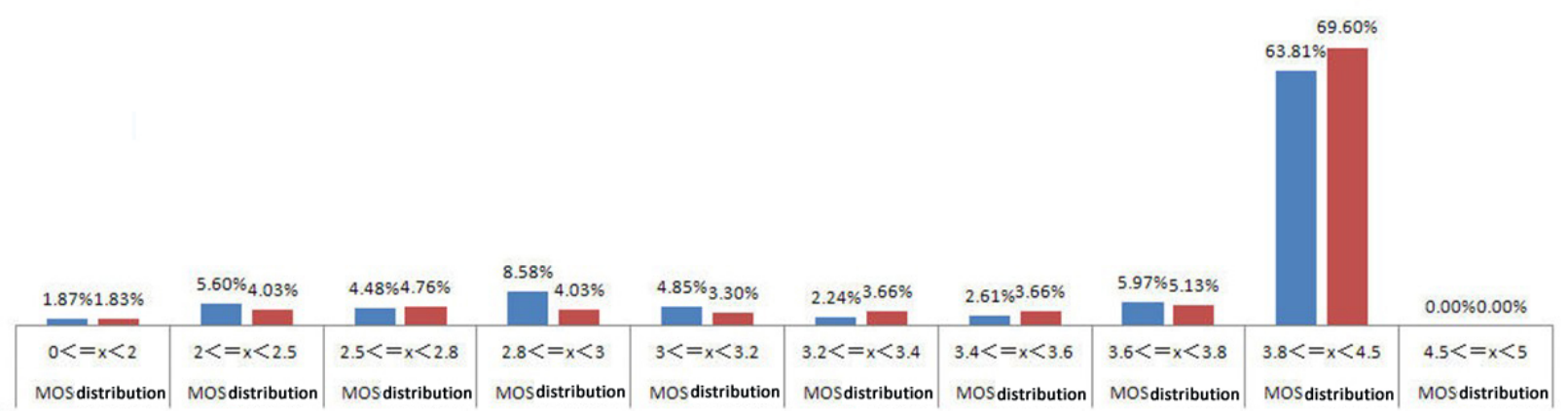

Fig. 2 MOS distribution contrast before and after the DTX opening

Table 2 MOS distribution contrast before and after the DTX opening 


\begin{tabular}{|c|c|c|c|c|c|c|c|c|c|c|c|}
\hline & & \multicolumn{10}{|c|}{ MOS distribution } \\
\hline & & $\begin{array}{l}0<= \\
x<2\end{array}$ & $\begin{array}{l}2<=x \\
<2.5\end{array}$ & $\begin{array}{l}2.5<=x \\
<2.8\end{array}$ & $\begin{array}{l}2.8< \\
=x<3\end{array}$ & $\begin{array}{l}3<=x \\
<3.2\end{array}$ & $\begin{array}{l}3.2<=x \\
<3.4\end{array}$ & $\begin{array}{l}3.4<=x \\
<3.6\end{array}$ & $\begin{array}{l}3.6<=x \\
<3.8\end{array}$ & $\begin{array}{l}3.8<=\mathrm{x} \\
<4.5\end{array}$ & $\begin{array}{l}4.5< \\
=x<5\end{array}$ \\
\hline \multirow{2}{*}{$\begin{array}{c}\text { Before } \\
\text { Openin } \\
\text { g }\end{array}$} & $\begin{array}{l}\text { Sampling } \\
\text { number }\end{array}$ & 5 & 15 & 12 & 23 & 13 & 6 & 7 & 16 & 171 & 0 \\
\hline & $\begin{array}{l}\text { proportion(\% } \\
\text { ) }\end{array}$ & $\begin{array}{r}1.87 \\
\% \\
\end{array}$ & $5.60 \%$ & $4.48 \%$ & $8.58 \%$ & $4.85 \%$ & $2.24 \%$ & $2.61 \%$ & $5.97 \%$ & $63.81 \%$ & $0.00 \%$ \\
\hline \multirow{2}{*}{$\begin{array}{c}\text { After } \\
\text { opening }\end{array}$} & $\begin{array}{l}\text { Sampling } \\
\text { number }\end{array}$ & 5 & 11 & 13 & 11 & 9 & 10 & 10 & 14 & 190 & 0 \\
\hline & $\begin{array}{l}\text { proportion(\% } \\
\text { ) }\end{array}$ & $\begin{array}{r}1.83 \\
\% \\
\end{array}$ & $4.03 \%$ & $4.76 \%$ & $4.03 \%$ & $3.30 \%$ & $3.66 \%$ & $3.66 \%$ & $5.13 \%$ & $69.60 \%$ & $0.00 \%$ \\
\hline
\end{tabular}

We analyze the contrast before and after the DTX opening, $3<=\mathrm{X}<5$ of the samples places $79.48 \%$ before the DTX opening. The result has increased to $85.35 \%$ after the DTX opening. The increase effect is remarkable.

0-7 level contrast of the call quality. 0-7 level contrast of the call quality before and after the DTX opening is in figure 3 and table 3.

0-7 level contrast of the call quality before and after the DTX opening

= Rate before opening (\%) $\quad$ = Rate after opening (\%)

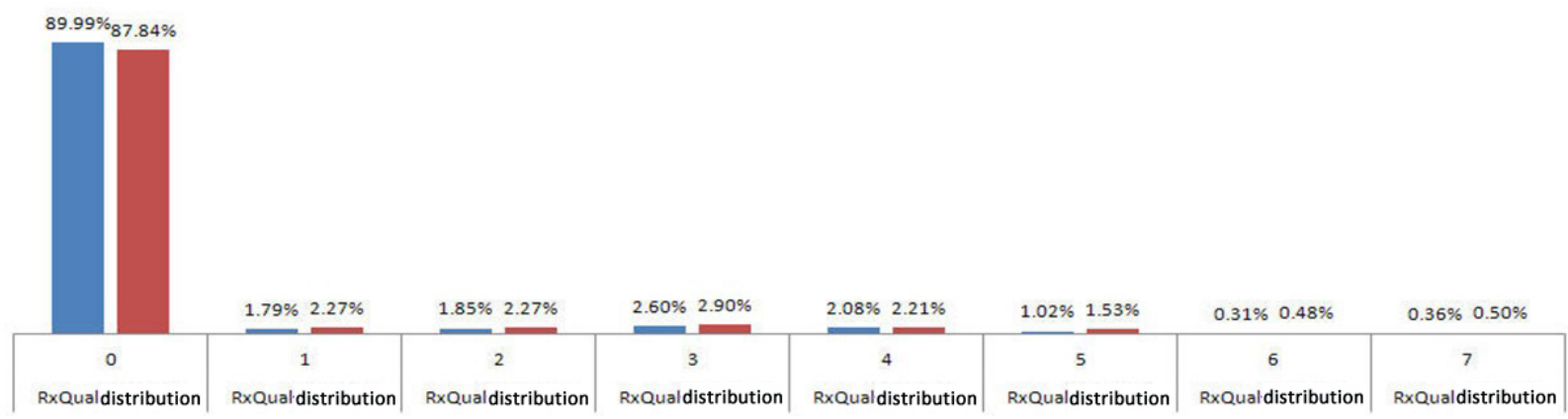

Fig. 3 0-7 level contrast of the call quality before and after the DTX opening

Table3 0-7level contrast before and after the DTX opening

\begin{tabular}{|c|c|c|c|c|c|c|c|c|c|}
\hline & & \multicolumn{8}{|c|}{ RxQual distribution } \\
\hline & & 0 & 1 & 2 & 3 & 4 & 5 & 6 & 7 \\
\hline \multirow{2}{*}{$\begin{array}{c}\text { Before } \\
\text { opening }\end{array}$} & $\begin{array}{l}\text { Sampling } \\
\text { number }\end{array}$ & 11485 & 228 & 236 & 332 & 266 & 130 & 39 & 46 \\
\hline & porportion(\%) & $\begin{array}{r}89.99 \\
\%\end{array}$ & $1.79 \%$ & $1.85 \%$ & $2.60 \%$ & $2.08 \%$ & $1.02 \%$ & $0.31 \%$ & $0.36 \%$ \\
\hline \multirow{2}{*}{$\begin{array}{c}\text { After } \\
\text { opening }\end{array}$} & $\begin{array}{l}\text { Sampling } \\
\text { number }\end{array}$ & 11372 & 294 & 294 & 376 & 286 & 198 & 62 & 65 \\
\hline & porportion(\%) & $\begin{array}{r}87.84 \\
\%\end{array}$ & $2.27 \%$ & $2.27 \%$ & $2.90 \%$ & $2.21 \%$ & $1.53 \%$ & $0.48 \%$ & $0.50 \%$ \\
\hline
\end{tabular}

We analyze the contrast before and after the DTX adjustment. The call quality of 6-7 level samples places $0.67 \%$ before the adjustment, which places $0.98 \%$ after the adjustment.

Other index contrast. Table 4 is the result of other index contrast before and after the DTX opening.

Table4 Other index contrast before and after the DTX opening

\begin{tabular}{|l|l|l|r|l|l|l|l|l|l|l|l|}
\hline & $\begin{array}{l}\text { Call } \\
\text { Attempt } \\
\text { time }\end{array}$ & $\begin{array}{l}\text { Call } \\
\text { dro } \\
\mathrm{p}\end{array}$ & $\begin{array}{l}\text { Access } \\
\text { failure }\end{array}$ & $\begin{array}{l}\text { Switch } \\
\text { Attempt } \\
\text { time }\end{array}$ & $\begin{array}{l}\text { Switch } \\
\text { success }\end{array}$ & $\begin{array}{l}\text { Location } \\
\text { update } \\
\text { request }\end{array}$ & $\begin{array}{l}\text { Location } \\
\text { update } \\
\text { success }\end{array}$ & reselection & $\begin{array}{l}\text { HR } \\
\text { sampling } \\
\text { point }\end{array}$ & $\begin{array}{l}\text { AMR } \\
\text { Sampling } \\
\text { point }\end{array}$ & Half rate \\
\hline $\begin{array}{l}\text { Before } \\
\text { opening }\end{array}$ & 16 & 0 & 0 & 198 & 195 & 22 & 22 & 19 & 138.475 & 44.633 & $2.85 \%$ \\
\hline $\begin{array}{l}\text { After } \\
\text { opening }\end{array}$ & 16 & 0 & 0 & 200 & 199 & 22 & 22 & 14 & 0 & 72.126 & $1.12 \%$ \\
\hline
\end{tabular}

\section{Experimental results}


MOS has great promotion after closing the DTX. Compare the experimental result, voice MOS quality increases $1.22 \%$, which means DTX opening have an adverse impact of the voice MOS quality. DTX opening will cut the voice signal, lose the voice frame, distort the voice and even influence the MOS rate test.

RxQuality decrease after closing the DTX. The experimental results show the RxQuality decreases 0.31\% based on the 6-7 level sampling points increasing. After the DTX closing, the interference cannot be reduced of the wireless signal channel. This will cause the sampling points increase of the low noise, which is under $-100 \mathrm{~dB}$.

\section{Conclusion}

If we open the DTX in the wireless network, it will import the test of comfort noise and voice activity detection. The voice activity detection cannot be absolutely correct, which is influenced by the background noise, system noise and other effects. This condition will cut the voice signal and lead the voice frames lose and voice distortion. It will influence the voice quality and MOS test seriously. DTX open will decrease the single voice quality, but it can promote the network C/I after the whole network DTX opening, which can improve the average voice quality. Through this research, it will promote the voice MOS value and voice quality if we use DTX technology in the network system of the mobile communications. It will reduce wireless system interference. At the same time, DTX technology development can improve the adaptation and controllability based on the various communications. This is an important significance to intensify the green communication theory of the mobile communication system and improve the user perception.

\section{References}

[1]Discontinous transmission Application in GSM System, Xu Bing, Telecommunications Informat ion,2000.02.25,8-11

[2]Discontinous Transmission in Speech Communication, Zhou Dejun, Communications Technolog y,No. 9 2001, 46-48

[3]Research on Enhancing the Mobile Voice Quality (MOS) Technology, Liu Dongdong, Master D egree Theses of Beijing University of Posts and Telecommunications, September 2012.

Comments: This article is the research results of "DTX Technology Application Research in the Mo bile Communication Network" that based on Jiujiang University Subject. The subject NO. is 2014K JYB004. 